\title{
Involvement of the central nervous system in chronic inflammatory demyelinating polyneuropathy: a clinical, electrophysiological and magnetic resonance imaging study
}

\author{
I E C Ormerod, H M Waddy, A G Kermode, N M F Murray, P K Thomas
}

\begin{abstract}
In a consecutive series of 30 patients with chronic inflammatory demyelinating polyneuropathy (CIDP) minor clinical evidence of CNS involvement was found in five. Cranial magnetic resonance imaging (MRI) was performed in 28 and revealed abnormalities consistent with demyelination in nine patients aged less than 50 years and abnormalities in five aged 50 years or over. Measurements of central motor conduction time (CMCT) were obtained in 18 and showed unilateral or bilateral abnormalities in six. It is concluded that subclinical evidence of central nervous system (CNS) involvement is common, at least in patients with CIDP in the United Kingdom, but that clinically evident signs of CNS disease are infrequent. The association of a multiple sclerosis-like syndrome with CIDP is rare.
\end{abstract}

Chronic inflammatory demyelinating polyneuropathy (CIDP) has close clinical and pathological resemblances to the GuillainBarré syndrome but pursues a chronic progressive or chronic relapsing course. ${ }^{1-4}$ In recent years a number of patients have been described with a multifocal central nervous system (CNS) disorder, the clinical features of which resemble multiple sclerosis (MS), ${ }^{5-7}$ in association with CIDP. The frequency of this association is not known. The occurrence of CNS lesions was not noted in any of the series of 53 cases of CIDP reported by Dyck et $\mathrm{al}^{3}$ or the series of 92 documented by McCombe et $a l^{4}$ All six of the selected patients with combined peripheral nervous system (PNS)/ CNS demyelination described by Thomas $e t$ $a l^{5}$ had CNS lesions demonstrated by magnetic resonance imaging (MRI). In a group of 16 patients with CIDP, Mendell et al ${ }^{6}$ found periventricular, subcortical or brainstem white matter lesions in six, of whom three had clinical or laboratory abnormalities considered to indicate MS. This series, however, was partially selected. ${ }^{8}$

In this study we have examined a consecutive unselected series of 30 patients, 28 of whom consented to MRI. Studies of central motor conduction time (CMCT) were also performed as CMCT was found to be abnormal in all four patients with CIDP and multifocal CNS demyelination reported by Thomas et al in which this was assessed. ${ }^{5}$

\section{Patients and methods}

Thirty consecutive patients with CIDP referred to one of us (PKT) formed the basis of this study (see table); of these, 28 consented to MRI studies. The diagnosis of CIDP was made according to the criteria of Dyck et al. ${ }^{3}$ This was based on the history, the clinical findings, nerve conduction studies and examination of the cerebrospinal fluid (CSF). Nerve biopsy was performed in 18 . The age of the patients at the time of the study was 9-83 (mean $37 \cdot 4$ ) years; 14 were male and 16 female. The series will be biased against childhood cases as the majority were derived from the National Hospital for Neurology and Neurosurgery where paediatric cases are under-represented.

Patients with a chronic demyelinating polyneuropathy associated with a paraproteinaemia or leukodystrophy or who had other possible causes for neuropathy, such as diabetes mellitus, were excluded.

Cranial MRI was performed using a 0.5 Tesla Picker MR imaging system. Multislice T2-weighted spin echo images (SE 2000/60) were obtained with a slice thickness of $5 \mathrm{~mm}$. The images were subjected to blind assessment by two of the authors (IECO and AGK) independently and only those images considered to be abnormal by both assessors were accepted as such. The images were evaluated for the number, pattern and distribution of abnormalities.

CMCT was measured with surface recording from the abductor digiti minimi muscle and magnetic stimulation of the motor cortex as previously described. ${ }^{9}$ The proximal motor roots were stimulated electrically in the region of the intervertebral foramina by high voltage $(300-400 \mathrm{~V})$ shocks applied transcutaneously over the cervical spine at the $\mathrm{C} 7 / \mathrm{T} 1$ interspace and the ulnar nerve was stimulated supramaximally at the wrist. CMCT was obtained by subtraction of the latency of the response evoked by cervical stimulation from that following activation of the cortex. The upper limit of normal was taken as $8.3 \mathrm{~ms}$ (mean CMCT $6.2 \mathrm{~ms}, \mathrm{SD} 0.86 \mathrm{~ms}$ in 46 sides of 32 subjects, aged $21-78$ years). This value contains a small peripheral component estimated, 
Table Summary of clinical, MRI and CMCT data

\begin{tabular}{|c|c|c|c|c|c|c|c|c|c|c|}
\hline Case & Sex & $\begin{array}{l}\text { Age } \\
\text { (years) }\end{array}$ & $\begin{array}{l}\text { Illness } \\
\text { duration } \\
\text { (years) }\end{array}$ & Course & $\begin{array}{l}C S F \\
\text { protein } \\
(\mathrm{g} / \mathrm{l})\end{array}$ & $\begin{array}{l}\text { Oligoclonal } \\
\text { CSF IgG }\end{array}$ & $\begin{array}{l}\text { Slowest } \\
M N C V^{\star \star} \\
\left(m s^{-1}\right)\end{array}$ & $M R I$ & $C M C T$ & $\begin{array}{l}\text { Clinical } \\
\text { CNS } \\
\text { involvement }\end{array}$ \\
\hline 1 & $\mathbf{M}$ & 30 & 1 & $\mathbf{P}$ & 0.56 & + & 31 & + & - & + \\
\hline 2 & $\mathbf{F}$ & 51 & 2 & $\mathbf{R}$ & 0.61 & - & 26 & + & - & - \\
\hline 3 & $\mathbf{F}$ & 43 & 11 & $\mathbf{R}$ & $1 \cdot 10$ & - & 20 & + & + & $(+)$ \\
\hline 4 & $\mathrm{~F}$ & 68 & 18 & $\mathbf{P}$ & 0.54 & - & 19 & + & ND & + \\
\hline 5 & $\mathbf{M}$ & 37 & 3 & $\mathbf{R}$ & 0.42 & - & 12 & + & ND & - \\
\hline 6 & M & 36 & 4 & $\mathbf{R}$ & 0.35 & + & 39 & + & - & - \\
\hline 7 & $\mathbf{F}$ & 36 & 4 & $\mathbf{P}$ & 0.40 & - & 25 & + & ND & + \\
\hline 8 & $\mathrm{~F}$ & 27 & 11 & $\mathbf{R}$ & 1.00 & - & 31 & + & - & - \\
\hline 9 & $\mathbf{M}$ & 20 & 10 & $\mathbf{R}$ & 0.68 & - & 24 & + & + & - \\
\hline 10 & $\mathbf{M}$ & 49 & 4 & $\mathbf{P}$ & 0.40 & - & 26 & + & ND & - \\
\hline 11 & M & 60 & 1 & $\mathbf{P}$ & 0.69 & - & 15 & + & + & - \\
\hline 12 & $\mathrm{~F}$ & 83 & 1 & $P$ & 0.56 & + & 23 & + & ND & - \\
\hline 13 & $\mathrm{~F}$ & 22 & 1 & $\mathbf{P}$ & 1.76 & - & 43 & - & - & - \\
\hline 14 & M & 22 & 2 & $\mathbf{R}$ & $2 \cdot 50$ & - & 20 & - & ND & - \\
\hline 15 & M & 24 & 2 & $\ddot{P}$ & 0.42 & - & 26 & - & - & - \\
\hline 16 & $\mathbf{M}$ & 55 & 3 & $\mathbf{P}$ & $2 \cdot 60$ & - & 32 & - & + & - \\
\hline 17 & $\mathbf{M}$ & 40 & 13 & $\mathbf{R}$ & 0.45 & - & 33 & - & - & - \\
\hline 18 & $\mathbf{F}$ & 23 & 1 & $\mathbf{M}$ & 3.20 & - & 34 & - & ND & - \\
\hline 19 & $\mathbf{F}$ & 51 & 22 & $\mathbf{R}$ & ND & ND & 36 & - & ND & - \\
\hline 20 & M & 28 & 2 & $\mathbf{R}$ & 1.00 & - & 29 & - & - & + \\
\hline 21 & $\mathrm{~F}$ & 21 & 11 & $\mathbf{R}$ & 0.40 & - & 41 & - & + & - \\
\hline 22 & F & 20 & 2 & $\mathbf{P}$ & $0 \cdot 30$ & - & 35 & - & - & - \\
\hline 23 & M & 32 & 4 & $\mathbf{R}$ & 1.70 & + & 36 & - & + & - \\
\hline 24 & $\mathbf{F}$ & 46 & 19 & $\mathbf{R}$ & $1 \cdot 10$ & - & 7 & - & - & - \\
\hline 25 & F & 9 & 1 & $\mathbf{R}$ & 0.66 & - & 22 & - & - & - \\
\hline 26 & $\mathbf{M}$ & 43 & 5 & $\mathbf{R}$ & ND & ND & 22 & - & - & - \\
\hline 27 & $\mathbf{F}$ & 68 & 2 & $\mathbf{M}$ & ND & ND & 34 & + & ND & + \\
\hline 28 & $\mathbf{M}$ & 32 & 2 & M & $2 \cdot 00$ & - & 24 & + & ND & - \\
\hline 29 & F & 33 & 3 & $\mathbf{R}$ & 0.79 & ND & 15 & ND & - & - \\
\hline 30 & F & 12 & 2 & $\mathbf{R}$ & $2 \cdot 80$ & ND & 17 & ND & ND & - \\
\hline
\end{tabular}

*The numbering is not in the order of admission to the study.

$\star \star M N C V=$ motor nerve conduction velocity, upper or lower limbs; $P=$ chronic progressive; $R=$ relapsing; $M=$ monophasic; $+=$ present (for oligoclonal CSF IgG, and clinical CNS involvement) or abnormal (for MRI and CMCT); ND = not done.

in the normal subject, to be about $0.4 \mathrm{~ms}$ from conduction in the roots ${ }^{10}$ and therefore correction of normative data is necessary where there is slowing of peripheral motor conduction. Proximal root conduction time was calculated as $1.0 \mathrm{~ms}$ for motor conduction velocity (neck-wrist) of $30 \mathrm{~ms}^{-1}$ and $1.5 \mathrm{~ms}$ for $20 \mathrm{~ms}^{-1}$ giving upper limits of CMCT of $8.9 \mathrm{~ms}$ and $9.4 \mathrm{~ms}$ respectively.

\section{Results}

\section{Clinical features}

The duration of illness ranged from 1 to 22 (mean 5.6) years. The clinical course was relapsing and remitting in 17 , and chronic progressive in 13. In three of the latter, spontaneous improvement occurred with a monophasic course. The mean age of onset in the relapsing cases was $25 \cdot 1$ years and 43.7 years in the chronic progressive cases (excluding the three patients with a monophasic course with spontaneous improvement).

Fourteen presented with weakness, four with combined weakness and sensory loss, nine with sensory disturbance and one with dysphonia. At some stage in the course of the illness, distal limb weakness was present in all and sensory disturbance was present in 20. Spontaneous pain was a complaint in 10 and upper limb postural tremor was observed in nine patients. Abnormalities of the cranial nerves were encountered in 16. Enlargement of peripheral nerves was noted only in three patients.

Evidence of involvement of the CNS was obtained in five (possibly six) cases: two had extensor plantar responses (Cases 1, 4; see table), one had an acute brainstem disturbance (Case 7; case 2, Waddy et $a l^{11}$ ), one showed downbeat nystagmus (Case 27) and one had sensory loss in the legs and lower trunk with an upper sensory level (Case 20). A further patient had generally exaggerated tendon reflexes but no other evidence of corticospinal tract damage (Case 3).

A possible precipitating event in association with one or more clinical episodes was noted in nine patients. These were smallpox vaccinations in two, pregnancy in two and nonspecific infections in the other five.

Nerve conduction studies were performed in all 30 patients. Motor conduction velocities were reduced in all (table) with values of 25 $\mathrm{ms}^{-1}$ or less in 11 . The slowest value recorded was $7 \mathrm{~ms}^{-1}$. The cerebrospinal fluid was examined in 25 patients. The CSF protein content was elevated $(>0.5 \mathrm{~g} / \mathrm{l})$ in 17 (table). Oligoclonal IgG bands were present in four patients. Only one of these had clinical evidence of CNS involvement (Case 1, table). Nerve biopsies were abnormal in the 18 cases in which they were obtained and showed a mixed pattern of demyelination and axonal loss. Minor hypertrophic changes were frequent but prominent "onion bulb" changes were seen in only two patients. Focal infiltrates of inflammatory cells were present in only two cases, but occasional mononuclear cells (monocytes and lymphocytes) were observed in the endoneurium in a number of the patients.

\section{Magnetic resonance imaging}

Fourteen out of the 28 patients had an abnormal MRI scan; of these, nine were aged 49 years or less. In the five older patients there were multiple discrete white matter lesions and irregular periventricular lesions in two (Cases 4, 11), smooth periventricular changes with multiple discrete cerebral white matter lesions in two (Cases 12, 27) and only discrete cerebral 

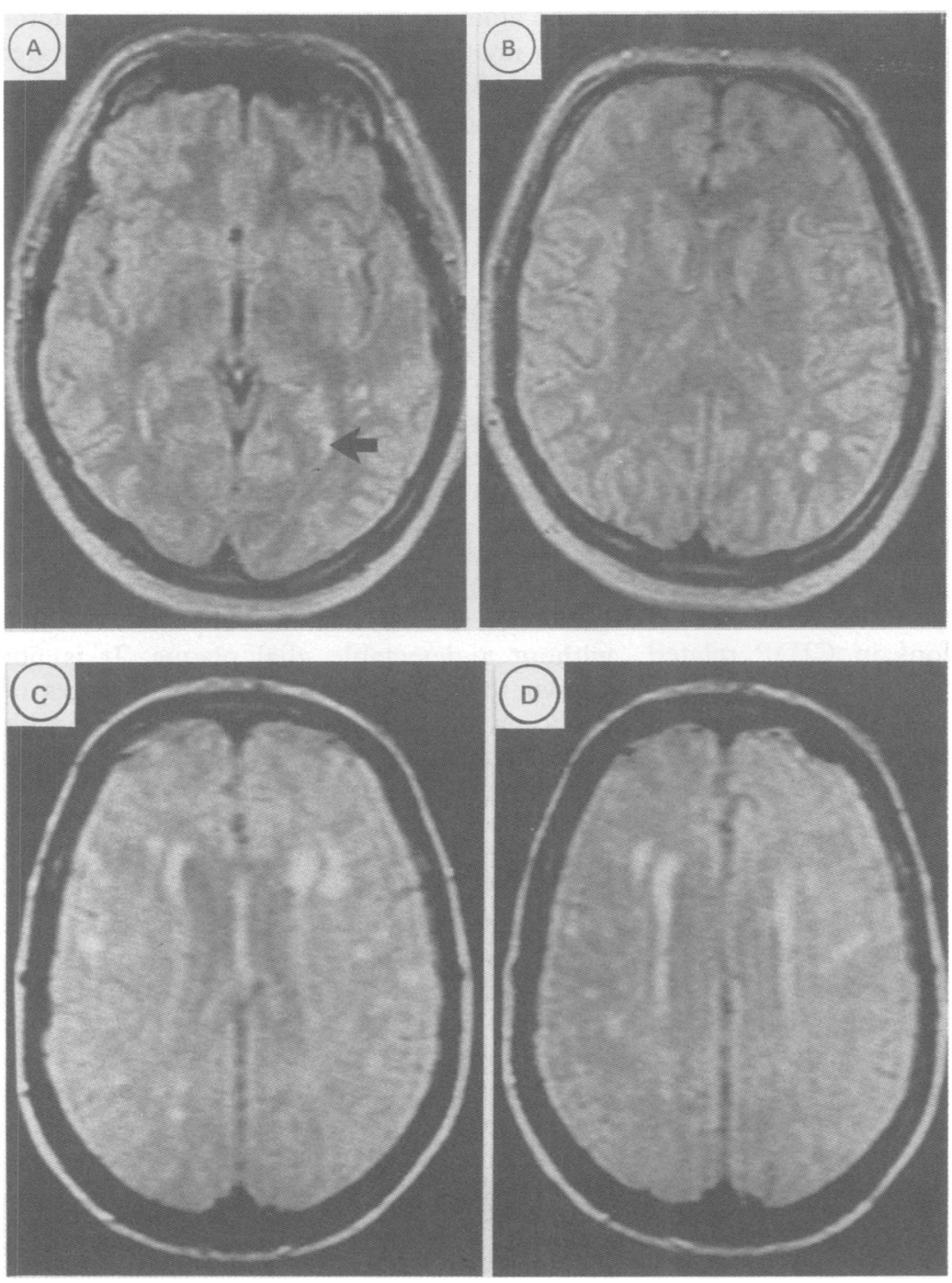

Figure 1 (a) Case 6. MRI image (SE 2000/60) showing irregular periventricular lesions (arrowed) around the trigones of the lateral ventricles. There are additional discrete lesions in the cerebral white matter. (b) Case 6. MRI image (SE 2000/60) showing multiple lesions within the cerebral white matter. $(c, d)$ Case 12. MRI images (SE 2000/60) demonstrating smooth periventricular abnormalities around the margins of the lateral ventricles. There are additional multiple lesions in the cerebral white matter which are separate from the margin of the ventricles.

white matter lesions in one patient (Case 2). There was a brainstem lesion in one patient (Case 11).

In the nine younger patients, discrete cerebral lesions without periventricular changes were present in two (Cases 3,9 ). The remaining seven patients (Cases $1,5-8,10,28$ ) all had irregular periventricular lesions of variable severity (fig 1). Additional discrete lesions within the cerebral white matter were seen in five of these seven patients (not seen in Cases 1 and 28). Lesions in the brainstem were seen in three patients (Cases $1,5,7$ ). Lesions within the cerebellar hemisphere were present only in Case 7.

Figure 2 Prolongation of CMCT at $10.8 \mathrm{~ms}$ (Case 11).

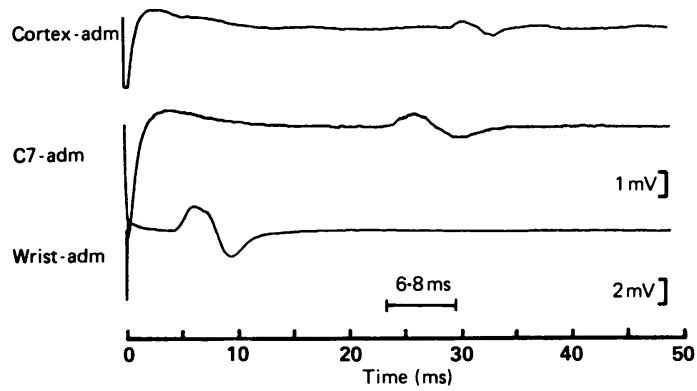

Figure 3 Preservation of normal CMCT, 6.8 ms despite marked prolongation of peripheral conduction with low amplitude dispersed muscle action potentials recorded from abductor digiti minimi (Case 13).

Nine of the 14 patients with abnormal cranial MRI had cranial nerve lesions at some time during their illness, compared with eight out of 14 with normal MRI. Clinical evidence of CNS involvement was seen in four of the 14 with abnormal MRI but only in one of the 14 with normal MRI.

Oligoclonal IgG bands were detected in the CSF in three out of the 14 patients with abnormal MRI findings but only in one of 14 with normal MRI.

\section{Central motor conduction time}

An attempt was made to measure CMCT in 23 of the 30 patients. The technique employed requires the ability to record a reproducible evoked muscle action potential from abductor digiti minimi on ulnar nerve stimulation. In four patients the degree of conduction block or denervation, or both, was such that this was not possible and CMCT therefore could not be assessed. Recordings were accordingly obtained from 18 patients and of these, six were abnormal. The most common abnormality was a moderate prolongation of latency (fig 2) which was unilateral in Cases 3, 11, 16 and 21 and bilateral in Cases 9 and 23. The amplitude of the evoked muscle action potential following magnetic brain stimulation was not a helpful parameter. The potential was frequently dispersed and of low amplitude, but identical in morphology to that obtained from cervical root stimulation and therefore reflecting the peripheral conduction abnormality (fig 3).

When the CMCT results were compared with the MRI findings, seven of the 14 patients with abnormal MRI also had CMCT recordings; of these, three were abnormal. Of the 14 patients with normal MRI, 11 had CMCT recordings of which three were abnormal. In the five patients with clinical evidence of CNS disease, a normal result was obtained in both of the two cases in which CMCT was measured.

\section{Discussion}

The clinical features in this series of patients with CIDP are similar to those in other reported series. A relapsing course was seen in 57\%, which is slightly higher than the figure of $34 \%$ found by Dyck and Arnason ${ }^{12}$ but close to the value of $65 \%$ given by McCombe et al. ${ }^{4}$ The age of onset in our patients was again earlier in 
the relapsing cases (25.1 years) than in those with a chronic progressive course ( 43.7 years). McCombe et al reported mean ages of onset of 26.8 and 51.4 years respectively. Possible precipitating factors were identified in $44 \%$ by McCombe et al, which is slightly higher than the present series $(32 \%)$.

The main purpose of this study was to assess the frequency of CNS involvement in CIDP. No cases with florid evidence of this, similar to those described by Thomas et $a l^{5}$ and Rubin et $a l^{7}$ were found. Minor CNS signs were encountered in five and were possibly present in one further case. In our series, cranial nerve involvement was found in $60 \%$, which is higher than in previous series. It was not always possible on clinical grounds to be certain whether this was the result of brainstem or extra-axial involvement. The occurrence of focal cranial nerve lesions in CIDP related both to CNS and peripheral lesions has been reported. ${ }^{11}$ MRI abnormalities were no commoner in the present patients who had cranial nerve involvement than in those who did not.

Mendell et al, ${ }^{6}$ Pakanlis et al ${ }^{13}$ and Barohn et $a l^{14}$ found that six out of 18 patients had abnormalities on MRI and that four of these also had clinical evidence of disease. However, four of the six were over 50 years of age and three over 70. In view of the high incidence of MRI abnormalities in older patients, these findings have to be interpreted with caution.

The nature and distribution of the MRI abnormalities found in the present series is of some importance. In six out of nine patients aged under 50 years there were irregular periventricular lucencies as well as other lesions within the brain. These appearances, although nonspecific, are indistinguishable from those seen in MS. In two out of these nine patients there were no periventricular lesions. This pattern of abnormality, which is even less specific, may also be encountered in MS. Of the older patients with abnormal MRI examinations, two out of five had smooth periventricular lesions of a type more frequently associated with vascular change than demyelination. This type of abnormality, sometimes combined with discrete lesions elsewhere in the brain, is also seen in some normal subjects and is of increasing frequency with age. Nevertheless, there was clinical evidence of CNS involvement in four of the patients with abnormal MRI findings but only in one of those without detectable abnormalities.

MRI and CMCT have both been available for some years, but this is the first time that they have been applied together systematically for the investigation of CNS involvement in CIDP. In our series, although some patients with MRI abnormalities also had delayed CMCT, there was not complete concordance between these techniques. This is not surprising as the two investigations demonstrate qualitatively different abnormalities within the nervous system. Furthermore, there is only a partial overlap in the anatomical territory encompassed by the two techniques. MRI demonstrates lesions where there are changes in the amount of tissue water and also alterations in the physical behaviour of water protons. Some of the lesions within the brain seen on MRI may be demyelinated mature plaques where myelin has been replaced by astrocytes, with relative preservation of the axons and a local increase in water content. ${ }^{15}$ Recent studies of serial MRI examinations in patients with established MS have shown that some lesions appear only briefly and may be undetectable on MRI within a matter of weeks. ${ }^{16}$ The pathological correlates of the evanescent lesions are not established but there is some evidence that the earliest change in the brain in the evolution of a lesion is a defect in the blood-brain barrier. Subsequent to the defect there is an increase in the tissue water content which may be partially extracellular and which in some instances appears to resolve without a detectable glial plaque. It is not known to what extent the various stages of evolution of such lesions will interfere with axonal function. Even in an established plaque there may be significant function retained by the residual axons. Abnormalities of CMCT demonstrate a functional disturbance in the central motor pathways. This technique has the additional advantage of including the cervical cord but of course will not demonstrate lesions within the brain which are outside the motor pathways. An abnormality of CMCT for corticospinal fibres to the $\mathrm{T} 1$ cord segment was detected in eight of the 19 patients from whom recordings were obtained.

Function in central pathways can also be examined by evoked potential studies. Visual (VEP) and brainstem auditory evoked potentials (BSAEP) were abnormal in all six of the cases of CIDP with multifocal CNS demyelination reported by Thomas et al. ${ }^{5}$ Somatosensory evoked potentials (SEP), when they could be recorded, were also abnormal, sometimes with very considerably prolonged latencies. VEP and BSAEP abnormalities in patients with CIDP have subsequently been reported by Pakanlis et al ${ }^{13}$ and Gigli et al. ${ }^{17}$

From this study and the previous reports employing MRI and evoked potential recordings, it can be concluded that although subclinical CNS abnormalities are common in CIDP and minor clinical abnormalities are observable in a small proportion, concurrent severe CNS disease is rare. Conversely, there have been reports dating back for many years of a demyelinating neuropathy affecting spinal roots $^{18-21}$ or more widely in the PNS ${ }^{22}{ }^{23}$ in patients with a primary diagnosis of MS. It is not yet clear whether the CNS lesions that may occur in patients with CIDP are morphologically similar to those of MS, but the severity of prolongation of SEP latencies indicates that they are demyelinating in nature. The temporal coincidence of the CNS and peripheral nerve disorder favours the operation of a single disease process or the existence of shared trigger mechanisms.

As has been pointed out before, there are interesting parallels between CIDP and MS. Thus, as confirmed in our study, the age of onset in the relapsing cases of CIDP is 
significantly less than that for the chronic progressive cases. A relapsing course in MS is commoner in younger individuals. A similar HLA haplotype (A3-DR2) may be found in $\mathrm{MS}^{24}$ and CIDP. ${ }^{25}$ The occurrence of oligoclonal IgG in the CSF is possibly less common in CIDP with multifocal CNS demyelination than in uncomplicated clinically definite MS. $^{5}$ There is evidence for involvement of the immune systems in the pathogenesis both of MS and CIDP. Whether there is a cross-reaction between the CNS and PNS in such overlap cases because of shared antigens remains to be established.

HMW was supported by the John Pennell Foundation. The MRI facility at the National Hospital was provided by the Multiple Sclerosis Society and is also supported by the Medical Research Council. We are grateful to the physicians at the National Hospital and elsewhere for referral of patients.

1 Austin JH. Recurrent polyneuropathies and their corticosteroid treatment: with five-year observations of a placebo-controlled case treated with corticotrophin, placebo-controlled case treated with corticot
cortisone, and prednisone. Brain 1958;81:157-92.

2 Thomas PK, Lascelles RG, Hallpike JF, Hewer RI Recurrent and chronic relapsing Guillain-Barré polyneuritis. Brain 1969;92:589-606.

3 Dyck PJ, Lais AC, Ohta M, Bastron JA, Okazaki H, Groover RV. Chronic inflammatory polyradiculopathy. Mayo Clin Proc 1975;50:621-37.

4 McCombe PA, Pollard JD, McLeod JG. Chronic inflammatory demyelinating polyradiculoneuropathy. Brain 1987;110:1617-30.

5 Thomas PK, Walker RHW, Rudge P, et al. Chronic demyelinating peripheral neuropathy associated with multifocal central nervous system demyelination. Brain 1987;110:53-76.

6 Mendell JR, Kolkin S, Kissel JT, Weiss KL, Chakeres DW, Rammohan KW. Evidence for central nervous system demyelination in chronic inflammatory demyelinating polyradiculoneuropathy. Neurology (Cleveland) 1987;
37:1291-4.

7 Rubin M, Karpati G, Carpenter S. Combined central and peripheral myelinopathy. Neurology (Cleveland) 1987;37 $1287-90$

8 Mendell JR. Personal communication. 1988

9 Hess CW, Mills KR, Murray NMF, Schriefer TN
Magnetic brain stimulation: central motor conduction studies in multiple sclerosis. Ann Neurol 1987;22:744-52. 10 Mills KR, Murray NMF. Electrical stimulation over the human vertebral column: which neural elements are excited? Electroenceph Clin Neurophysiol 1986;63:582-9.

11 Waddy HM, Misra VP, King RHM, Thomas PK, Middleton L, Ormerod IEC. Focal cranial nerve involvement in chronic inflammatory demyelinating polyneuropathy: clinical and MRI evidence of peripheral and central lesions. $J$ Neurol 1989;236:400-5.

12 Dyck PJ, Arnason B. Chronic inflammatory demyelinating polyradiculoneuropathy. In: Dyck PJ, Thomas PK, Lambert EH, Bunge R, eds. Peripheral Neuropathy 2nd edit. Philadelphia: WB Saunders, 1984;2101-14.

13 Pakanlis A, Drake ME, Barohn RJ, Chakeres DW, Mendell JR. Evoked potentials in chronic inflammatory demyelinating polyneuropathy. Arch Neurol 1988;45:1014-6.

14 Barohn RJ, Kissel JT, Warmolts JR, Mendell JR. Chronic inflammatory polyradiculopathy: clinical characteristics, course, and recommendations for diagnostic criteria. Arch Neurol 1989;46:878-84.

15 Ormerod IEC, Miller DH, McDonald WI, et al. The role of NMR imaging in the assessment of multiple sclerosis and isolated neurological lesions. A quantitative study. Brain 1987;110:1579-1616.

16 Miller DH, Rudge P, Johnson G, et al. Serial gadolinium enhanced magnetic resonance imaging in multiple sclerosis. Brain 1988;111:927-39.

17 Gigli GL, Carlesimo A, Valente M, et al. Evoked potentials suggest cranial nerve and CNS involvement in chronic suggest cranial nerve and CNS involvement in chronic relapsing.

18 Ketalaer CJ, Leruitte A, Perier O. Histopathologie de la moelle lombosacrée et de la queue de cheval dans une série de cas verifiés de sclérose en plaques. Acta Neurol Scand 1966;42(suppl 20):33-51.

19 Ninfo V, Rizzuto N, Terzian H. Associazione anatomoclinica di nevrite ipertrofica e sclerosi a placche. Acta Neurol (Naples) 1967;22:228-37.

20 Schoene WC, Carpenter C, Behan PO, Geschwind N. Onion bulb formations in central and peripheral nervous system in association with multiple sclerosis and hypertrophic polyneuropathy. Brain 1977;100:755-73.

21 Rosenberg NL, Bourdette D. Hypertrophic neuropathy and multiple sclerosis. Neurology (Cleveland) 1983;33: and mul $1361-4$.

22 Lassmann H, Budka H, Schnaberth G. Inflammatory demyelinating polyradiculitis in a patient with multiple sclerosis. Arch Neurol (Chicago) 1981;38:99-102.

23 Ro YI, Alexander CB, Oh SJ. Multiple sclerosis and hypertrophic demyelinating peripheral neuropathy. Muscle Nerve 1983;6:312-6.

24 McDonald WI. Multiple sclerosis: epidemiology and HLA associations. Ann NY Acad Sci 1984;436:109-17.

25 Feeney DJ, Pollard JG, McLeod JG, et al. HLA antigens in chronic inflammatory demyelinating polyneuropathy. $J$ Neurol Neurosurg Psychiatry 1990;53:170-2. 